J. Lake Sci. (湖泊科学), 2020, 32(3): 688-700

DOI 10. 18307/2020. 0309

(c) 2020 by Journal of Lake Sciences

\title{
东巢湖沉积物一水界面氮、磷、氧迁移特征及意义”
}

\author{
李运奔 ${ }^{1,2}$, 匡 帅 $^{3}$, 王臻宇 ${ }^{4}$, 申秋实 ${ }^{2,5 * *}$, 王亚东 ${ }^{2}$, 康得军 ${ }^{1,6}$ \\ (1: 福州大学土木工程学院, 福州 350116) \\ (2: 中国科学院南京地理与湖泊研究所湖泊与环境国家重点实验室, 南京 210008) \\ (3:武汉市汉阳市政建设集团有限公司,武汉 430050) \\ (4:德累斯顿工业大学城市与工业水管理研究院,德累斯顿 01069) \\ (5: 中国科学院中非联合研究中心, 武汉 430074) \\ (6:福州大学晋江科教园,晋江 362251)
}

摘 要: 以东巢湖近城市湖湾沉积物为研究对象, 在沉积物氮、磷营养盐分析的基础上, 采用沉积物柱状芯样静态释放模 拟法定量评估研究区域沉积物一水界面氨氮、溶解性活性磷酸盐营养盐释放潜力, 利用微电极非损伤测定技术获得沉积 物一水微界面溶解氧 (DO) 剖面分布及微界面 DO 消耗和扩散特征. 结果表明: 东巢湖近城市湖湾沉积物氮、磷污染物蓄 积量较高, 受 TN、TP 污染程度较重. 沉积物内源氨氮、磷酸盐释放明显, 平均释放速率分别达到 $32.44 \mathrm{mg} /\left(\mathrm{m}^{2} \cdot \mathrm{d}\right)$ 和 1.25 $\mathrm{mg} /\left(\mathrm{m}^{2} \cdot \mathrm{d}\right)$, 区域内沉积物已成为水柱中氮、磷营养盐的污染源. 研究区域上覆水体处于好氧状态, 沉积物一水微界面平 均 DO 穿透深度 $(\mathrm{OPD})$ 达到 $5.3 \mathrm{~mm}$, 平均 DO 扩散通量为 $4.56 \mathrm{mmol} /\left(\mathrm{m}^{2} \cdot \mathrm{d}\right)$, 表现出良好的 DO 扩散能力. 沉积物内源氨 氮和磷酸盐释放能力与表层沉积物 TN/TP 物质含量及沉积物一水微界面 DO 穿透深度有关, 在沉积物氮、磷污染较重的 情况下,DO 穿透深度越低越有利于氮、磷污染物从沉积物向上覆水体释放.

关键词: 沉积物;沉积物一水界面;营养盐; 溶解氧; 巢湖

\section{Characteristics and significance of nitrogen, phosphorus and oxygen transportation at the sediment-water interface in east Lake Chaohu*}

\author{
LI Yunben ${ }^{1,2}$, KUANG Shuai ${ }^{3}$, WANG Zhenyu ${ }^{4}$, SHEN Qiushi ${ }^{2,5 *}$, WANG Yadong ${ }^{2}$ \& KANG Dejun ${ }^{1,6}$ \\ (1: College of Civil Engineering, Fuzhou University, Fuzhou 350116, P.R. China) \\ (2: State Key Laboratory of Lake Science and Environment, Nanjing Institute of Geography and Limnology, Chinese Academy \\ of Sciences, Nanjing 210008, P.R. China) \\ (3: Wuhan Hanyang Municipal Construction Group Co, Ltd., Wuhan 430050, P.R.China) \\ (4: Institute of Urban and Industrial Water Management, Dresden 01069, Germany) \\ (5: Sino-Africa Joint Research Center, Chinese Academy of Sciences, Wuhan 430074, P.R. China) \\ (6: Jinjiang Science and Education Park of Fuzhou University, Jinjiang 362251, P.R.China)
}

\begin{abstract}
A comprehensive study of transportation features of nitrogen, phosphorous and dissolve oxygen at the sediment-water interface was carried out in near city areas of east Lake Chaohu. Based on the investigation of sediment nutrients analysis and nutrients release incubation experiments, the release potential and release rates of ammonia nitrogen $\left(\mathrm{NH}_{3}-\mathrm{N}\right)$ and soluble reactive phosphorous (SRP) of different sediments were estimated. The distribution characteristics, diffusion fluxes, and consumption rates of dissolved oxygen (DO) at the sediment-water interface of different sediments were studied by using a non-invasive microelectrode analysis system. The results showed the surface sediments in the near city areas of east Lake Chaohu were in severe nitrogen and phosphorous pollution with high total nitrogen ( TN) and total phosphorus (TP) loadings. Typical internal releases of $\mathrm{NH}_{3}-\mathrm{N}$ and
\end{abstract}

* 2019-09-07 收稿;2019-11-26 收修改稿.

国家重点研发计划项目(2016YFE0123300)、国家自然科学基金项目 (41877488)、中国科学院海外科教基地建设项 目 (SAJC201609) 和江苏省科技计划项目 (BZ2018057) 联合资助.

** 通信作者; E-mail:qsshen@ niglas.ac.cn. 
SRP were observed from all sediments with the average release rates of $32.44 \mathrm{mg} /\left(\mathrm{m}^{2} \cdot \mathrm{d}\right)$ and $1.25 \mathrm{mg} /\left(\mathrm{m}^{2} \cdot \mathrm{d}\right)$, respectively. The sediments play the role of pollution source rather than the sink for $\mathrm{NH}_{3}-\mathrm{N}$ and SRP in the study area. Results also showed that all overlying water were at aerobic condition. The average oxygen penetration depth (OPD) and oxygen diffusion flux at sedimentwater micro-interfaces reached $5.3 \mathrm{~mm}$ and $4.56 \mathrm{mmol} /\left(\mathrm{m}^{2} \cdot \mathrm{d}\right)$ respectively, indicating good DO diffusion ability from the boundary layer to the sediment. The internal release intensity of $\mathrm{NH}_{3}-\mathrm{N}$ and SRP are influenced by TN/TP contents of the surface sediment as well as the OPD at the sediment-water interface. The release of $\mathrm{NH}_{3}-\mathrm{N}$ and SRP from sediments could be benefited from the high nitrogen and phosphorous loadings and low OPD and contribute to the eutrophication of the lake.

Keywords: Sediment; sediment-water interface; nutrients; dissolved oxygen; Lake Chaohu

水体富营养化及蓝藻水华依旧是当前全球淡水湖泊所面临的最主要生态环境问题. 据第二次全国湖泊 调查显示: 我国大部分湖泊处于富营养化状态, 其中长江中下游浅水湖泊富营养化态势严峻 ${ }^{[1]}$. 氮 (N)、磷 (P) 营养盐浓度较高是湖泊水体富营养化及有害藻类暴发大规模水华的根本原因,外源输人与内源释放被 认为是湖泊水体氮、磷营养盐升高的两大物源基础. 普遍认为: 外源输人主要来自于工农业生产及城镇生活 源排放; 而内源释放则主要来自湖泊沉积物中相应污染物的迁移与转化, 并通过扩散、对流及再悬浮等形式 向上覆水体重新释放氮、磷营养盐 ${ }^{[2-4]}$. 已有研究表明, 在湖泊外源氮、磷输人得到有效控制的情况下, 内源 氮、磷释放可能依旧会维持水体富营养化长达数年甚至数十年之久 ${ }^{[5-6]}$, 因此湖泊沉积物内源营养盐释放对 上覆水体富营养化的影响不容忽视.

浅水湖泊沉积物一水界面是氮、磷等生源要素迁移转化的重要场所, 复杂而频繁变化的界面环境条件对 水体中的氮、磷循环有重要的影响 ${ }^{[7-9]}$. 沉积物一水界面氮、磷释放及内源负荷特征是富营养化湖泊持续的研 究热点之一, 沉积物氮、磷污染蓄积程度明显地影响着相应营养盐在沉积物和上覆水体中的迁移与扩散. 当 沉积物中氮、磷负荷较高时, 相应营养盐通过沉积物一水界面向上覆水体释放的潜力明显增加 ${ }^{[10-13]}$. 一般认 为,沉积物一水界面 $\mathrm{N} / \mathrm{P}$ 释放同时受到环境因素和内部因素的共同影响: 环境因素主要有温度 ${ }^{[14]} 、 \mathrm{pH}^{[15]}$ 、溶 解氧 (DO $)^{[16-17]}$ 、氧化还原电位 $\mathrm{Eh}^{[18]}$ 以及水动力扰动 ${ }^{[19-20]}$ 等; 内部因素主要包括沉积物中的氮、磷形态分 布 ${ }^{[21-22]}$ 、间隙水的氮磷浓度 ${ }^{[23-24]}$ 以及生物扰动 ${ }^{[3]}$ 等, 其中水中的 DO 被认为是最主要的因素之一 ${ }^{[25]}$. 沉积 物一水微界面的 DO 分布状态往往很大程度上控制了氧化还原电位的高低, 而沉积物一水界面间大多数溶解 性物质的转化及扩散迁移均受到其氧化还原电位的驱使 ${ }^{[26]}$. 对于湖泊生态系统来说, DO 参与了大多数生 源要素的主要生物地球化学循环过程, 沉积物中 DO 的分布状态可直接影响氮、磷等物质的迁移与转 化 ${ }^{[27-28]}$. 有研究表明, 水柱中 DO 浓度的变化亦可影响沉积物内源氮、磷营养盐释放速率 ${ }^{[17,29-30]}$, 而 DO 穿透 深度 (OPD) 进一步影响着间隙水中包括磷素在内的生源要素的平衡 ${ }^{[31-33]}$. 然而, 有关沉积物一水界面氮、磷 营养盐及 DO 迁移扩散耦合关系的研究较少, 相关研究还存在一定的空白,需要进一步补充与完善.

本文以典型富营养化的东巢湖近城市湖湾为研究区域, 以该区域沉积物为研究对象, 通过原位柱状样 静态培养及沉积物一水微界面分析, 研究其沉积物一水界面氮、磷、氧扩散迁移规律、定量估算相应释放速 率/扩散通量并分析其潜在影响, 进一步加深研究区域沉积物内源释放及其影响的理解与认识, 为东巢湖富 营养化问题的治理提供一定的理论依据.

\section{1 材料与方法}

\section{1 研究区域}

巢湖是我国五大淡水湖之一, 位于安徽省中部, 地处中国长江与淮河之间的洪泛平原上, 面积约 774 $\mathrm{km}^{2}$, 平均水深约 $3 \mathrm{~m}^{[34]}$. 改革开放以来, 受周围农业面源和城市点/面源营养盐排放的影响, 巢湖经历并遭 受了严重的富营养化问题 ${ }^{[35]}$. 本次研究区域为靠近巢湖市的巢湖东部近城市水域, 共在研究区域设置了 7 个采样点位, 分别为 $\mathrm{CH} 1 、 \mathrm{CH} 2 、 \mathrm{CH} 3 、 \mathrm{CH} 4 、 \mathrm{CH} 5 、 \mathrm{CH} 6$ 和 $\mathrm{CH} 7$, 其中 $\mathrm{CH} 1 、 \mathrm{CH} 2$ 和 $\mathrm{CH} 4$ 点位分别靠近裕溪河、 双桥河和柘臬河河口,7 个采样点较均匀分布于整个研究区域(图 1).

\section{2 沉积物样品采集}

利用重力式沉积物采样器 ( L $50 \mathrm{~cm} \times \Phi 8.4 \mathrm{~cm}$ ) 在各采样点采集沉积物柱状芯样 2 根 (深度 $>20 \mathrm{~cm}$,一 根用于沉积物释放培养, 另外一根用于沉积物一水微界面 DO 分析). 采样过程保证无扰动并带原位上覆水 


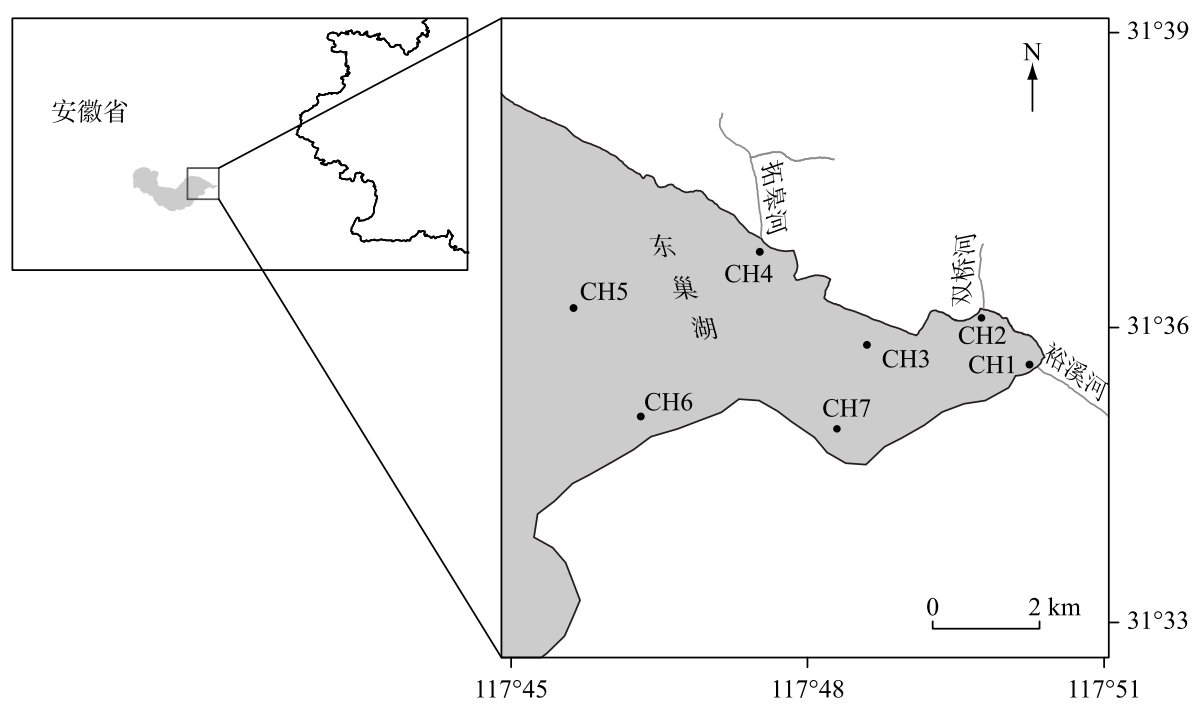

图 1 东巢湖近城市湖湾采样点分布

Fig. 1 Distribution of sampling sites in near city areas of east Lake Chaohu

以保持沉积物一水界面完整无损. 采集到柱状芯样后, 将每根柱样垂直放人支架内, 并且在尽量减少扰动的 情况下带回实验室. 在每个沉积物柱状样采样点, 同步采集水面以下 $20 \mathrm{~cm}$ 处原位上覆水 $5 \mathrm{~L}$, 装于用原位 湖水润洗过的聚乙烯水桶中带回实验室, 用于氮、磷释放培养实验.

\section{3 沉积物氮、磷释放模拟}

1.3.1 静态释放模拟 本研究采用静态释放模拟的方式进行沉积物氮、磷营养盐释放实验. 具体操作过程如 下. 首先, 使用虹吸法抽去柱状样中原上覆水, 再沿壁小心滴注已过滤去大颗粒物质的原位水样, 至液面高 度距沉积物表面 $20 \mathrm{~cm}$ 处停止 (此时水柱体积为 $1.13 \mathrm{~L}$ ), 标注刻度, 室温蔽光培养. 即刻取原水样作起始 样, 此后在指定时间取样 $(0 、 6 、 12 、 24 、 36 、 48 、 60$ 和 $72 \mathrm{~h})$, 每次取样体积为 $50 \mathrm{~mL}$, 其后用原样点初始过滤水 样补充至刻度. 即刻用 $0.45 \mu \mathrm{m}$ 水系混合纤维滤膜过滤所取水样并冷冻储存于冰柜, 待实验结束后统一分 析其中氨氮 $\left(\mathrm{NH}_{3}-\mathrm{N}\right)$ 及溶解性活性磷酸盐 $(\mathrm{SRP})$ 的浓度.

1.3.2 释放速率计算方法 沉积物一水界面氮、磷释放速率计算使用以下公式 ${ }^{[36]}$ :

$$
R=\left[V\left(C_{n}-C_{0}\right)+\sum_{j=1}^{n} V_{j-1}\left(C_{j-1}-C_{\mathrm{a}}\right)\right] /(A \cdot t)
$$

式中, $R$ 为释放速率 $\left(\mathrm{mg} /\left(\mathrm{m}^{2} \cdot \mathrm{d}\right)\right) ; V$ 为柱中上覆水体积 $(\mathrm{L}) ; C_{n} 、 C_{0} 、 C_{j-1}$ 分别为第 $n$ 次、初始和 $j-1$ 次采样时 $\mathrm{NH}_{3}-\mathrm{N}$ 或 $\mathrm{SRP}$ 的浓度 $(\mathrm{mg} / \mathrm{L}) ; C_{\mathrm{a}}$ 为水样中所添加物质的浓度 $(\mathrm{mg} / \mathrm{L}) ; V_{j-1}$ 为第 $j-1$ 次采样体积 $(\mathrm{L}) ; A$ 为沉 积物一水界面接触面积 $\left(\mathrm{m}^{2}\right) ; t$ 为释放时间 $(\mathrm{d})$.

\section{4 沉积物一水微界面溶解氧分析}

1.4.1 沉积物一水微界面溶解氧测定 用丹麦 Unisense 微电极系统来分析沉积物一水微界面处 DO 分布特征. 该监测系统通过 DO 传感电极在沉积物纵向连续测定得到相应深度 DO 的浓度, 测定过程中不消耗氧气. 在 测定过程前, 按要求先将电极极化 $2 \mathrm{~h}$ 以上, 然后使用零 DO 溶液 ( $0.1 \mathrm{~mol} / \mathrm{L} \mathrm{Na}_{2} \mathrm{SO}_{4}$ 溶液) 和饱和 DO 溶液 (以 $5 \mathrm{~L} / \mathrm{min}$ 速率百通空气 $5 \mathrm{~min}$ 以上的同采样点原位湖水) 进行校正, 以保证系统测量数值准确. 本测定系 统采用全自动推进器控制, 设定测量步长 $100 \mu \mathrm{m}$ 、电机推进速度 $100 \mu \mathrm{m} / \mathrm{s}$ 、停留时间 $1 \mathrm{~s}$ 、测量时间 $1 \mathrm{~s}$ 、测量 深度 $12000 \mu \mathrm{m}$, 测量过程保持安静无扰动. 在测量过程中, 对每个柱状样进行 3 次平行测定, 以保证所获得 数据的质量.

1.4.2 沉积物溶解氧消耗速率计算 沉积物中 DO 消耗速率使用 Berg 等开发的 PROFILE 软件进行计算, 有 关计算原理及方法见参考文献 [37]. 
1.4.3 微界面溶解氧扩散通量计算 沉积物一水微界面 DO 扩散通量计算使用以下公式 ${ }^{[38]}$ :

$$
J=D \frac{C_{\mathrm{W}}-C_{\mathrm{SWI}}}{\delta_{\mathrm{DBL}}} \times 10^{3}
$$

式中, $J$ 为沉积物一水微界面 DO 扩散通量 $\left(\mathrm{mmol} /\left(\mathrm{m}^{2} \cdot \mathrm{d}\right)\right), C_{\mathrm{W}}$ 和 $C_{\mathrm{SWI}}$ 分别为底栖边界层 (benthic boundary layer, BBL) 水体中和沉积物一水微界面 ( sediment-water interface, SWI) 处的 DO 浓度 $\left(\mathrm{mmol} / \mathrm{m}^{3}\right), \delta_{\mathrm{DBL}}$ 为扩散 边界层 (diffusion boundary layer, DBL) 的厚度 $(\mathrm{mm}), D$ 为溶解氧分子扩散系数 $\left(\mathrm{m}^{2} / \mathrm{d}\right)($ 该系数随温度和盐 度的变化而变化,其值参考文献 [39]).

\section{5 样品分析}

1.5.1 沉积物样品分析 本研究主要分析沉积物含水率、孔隙度、烧失量 (LOI) 等基本物理性质及总氮 $(\mathrm{TN}) 、$ 总磷 $(\mathrm{TP})$ 等基本化学性质. 对于含水率, 采用 $105^{\circ} \mathrm{C}$ 恒温热重法进行分析, 孔隙度根据含水率进行计 算. 之后, 将分析过含水率的沉积物干样放于陶瓷研钵中研磨, 并过 100 目尼龙网笁, 制备得到沉积物粉末 样品, 用于下一步分析. 称取 $2 \sim 5 \mathrm{~g}$ 沉积物粉末样品于陶瓷坩埚中, 用 $550^{\circ} \mathrm{C}$ 灼烧法分析其烧失量, 上述 3 项 测定参照文献 [ 40$]$. 沉积物 TN 和 TP 含量分别采用碱性过硫酸钾消解紫外分光光度法和过硫酸钾消解钼 锑抗分光光度法测定 ${ }^{[41]}$.

1.5.2 水样分析 本研究水样分析主要涉及水体中的 $\mathrm{NH}_{3}-\mathrm{N}$ 和 $\mathrm{SRP}$ 浓度 其中, $\mathrm{NH}_{3}-\mathrm{N}$ 浓度采用纳氏试剂比 色法测定, SRP 浓度采用钼锑抗分光光度法测定,具体测定过程参照文献 [42].

\section{6 数据分析}

东巢湖近城市湖湾采样点示意图采用 ArcGIS 10.3 软件绘制; 所有其他图形和一元方差分析均采用 OriginLab 9.1 软件完成; 相关性分析在 SPSS 22.0 软件中完成.

\section{2 结果}

\section{1 表层沉积物基本理化性质}

东巢湖近城市湖湾沉积物基本性质分析结果如表 1 所示. 除个别点位外、各采样点沉积物含水率、孔隙 度与有机质含量普遍较高, 平均值分别达到 $59.79 \% 、 78.00 \%$ 和 $4.88 \%$. 含水率、孔隙度与有机质分布呈现一 定的空间异质性,空间变异系数分别为 20.93\%、12.14\% 和 35.13\%. 其中靠近湖岸边的 CH6、CH7 的沉积物 含水率 $(72.75 \% 、 73.95 \%)$ 、孔隙度 $(86.97 \% 、 87.65 \%)$ 和 LOI $(6.55 \% 、 7.13 \%)$ 较其他采样点高, 反映其具有一 定的流动能力且有机质污染程度较高; 东面的双桥河与裕溪河河口采样点 $\mathrm{CH} 1$ 与 $\mathrm{CH} 2$ 的沉积物含水率、孔 隙度与有机质相近; 相比较而言, 柘臬河河口处 CH4 的沉积物含水率、孔隙度和有机质较低, 分别为 $37.12 \% 、 59.61 \%$ 和 $2.09 \%$.

分析结果表明, 研究区域各采样点沉积物 TN、TP 含量整体较高, 平均含量分别达到 3245.36 和 535.29

表 1 东巢湖近城市湖湾表层沉积物理化指标

Tab.1 Physicochemical properties of surface sediments in near city areas of east Lake Chaohu

\begin{tabular}{cccccc}
\hline 采样点位 & 含水率 $/ \%$ & 孔隙度 $/ \%$ & $\mathrm{LOI} / \%$ & $\mathrm{TN} /(\mathrm{mg} / \mathrm{kg})$ & $\mathrm{TP} /(\mathrm{mg} / \mathrm{kg})$ \\
\hline $\mathrm{CH} 1$ & 63.63 & 81.39 & 5.02 & 1783.54 & 319.51 \\
$\mathrm{CH} 2$ & 60.50 & 79.29 & 5.16 & 3249.69 & 607.98 \\
$\mathrm{CH} 3$ & 54.45 & 74.93 & 3.49 & 2597.55 & 483.70 \\
CH4 & 37.12 & 59.61 & 2.09 & 1608.06 & 431.67 \\
CH5 & 56.13 & 76.18 & 4.76 & 4399.73 & 638.17 \\
CH6 & 72.75 & 86.97 & 6.55 & 4326.21 & 539.16 \\
CH7 & 73.95 & 87.65 & 7.13 & 4752.74 & 726.83 \\
平均值 & 59.79 & 78.00 & 4.88 & 3245.36 & 535.29 \\
最大值 & 73.95 & 87.65 & 7.13 & 4752.74 & 726.83 \\
最小值 & 37.12 & 59.61 & 2.09 & 1608.06 & 319.51 \\
变异系数 & $20.93 \%$ & $12.14 \%$ & $35.13 \%$ & $39.80 \%$ & $25.58 \%$ \\
\hline
\end{tabular}


$\mathrm{mg} / \mathrm{kg}$, TN 、TP 含量最高点均为 $\mathrm{CH} 7$, 分别为 4752.74 和 $726.83 \mathrm{mg} / \mathrm{kg}$. 评价标准参考文献 [ 43] : CH2、CH3、 CH5 、CH6 和 CH7 点位的沉积物 TN 处于重度污染状态 ( TN $>2000 \mathrm{mg} / \mathrm{kg}$ ), CH1、CH4 点位的沉积物 TN 处于 中度污染状态 $(1000 \mathrm{mg} / \mathrm{kg} \leqslant \mathrm{TN} \leqslant 2000 \mathrm{mg} / \mathrm{kg})$; 除 CH1 点位的沉积物 TP 处于正常状态外 $(\mathrm{TP}<420$ $\mathrm{mg} / \mathrm{kg}$ ), 其他点位 TP 均处于污染状态, 其中 $\mathrm{CH} 2 、 \mathrm{CH} 3 、 \mathrm{CH} 5 、 \mathrm{CH} 6$ 点位的沉积物 TP 处于中度污染状态 ( 420 $\mathrm{mg} / \mathrm{kg} \leqslant \mathrm{TP} \leqslant 650 \mathrm{mg} / \mathrm{kg}$ ), CH7 点位的沉积物 $\mathrm{TP}$ 处于重度污染状态 ( TP $>650 \mathrm{mg} / \mathrm{kg}$ ). 从空间分布来看, 研 究区域沉积物 TN 和 TP 含量的空间分布差异较大, 其空间变异系数分别达到 39.08\% 和 25.58\%. 其中, 远离 河口的 CH5、CH6、CH7 点位的沉积物 TN 和 TP 含量高于河口附近采样点 CH1、CH3、CH4. 值得注意的是, 柘 臮河河口 CH4 采样点沉积物的 TN $(1608.06 \mathrm{mg} / \mathrm{kg})$ 和 TP $(431.67 \mathrm{mg} / \mathrm{kg})$ 含量均较低.

\section{2 沉积物氨氮和磷酸盐释放特征}

本研究区域东巢湖近城市湖湾各采样点 $\mathrm{NH}_{3}-\mathrm{N}$ 和 $\mathrm{SRP}$ 释放速率如图 2 所示. 整个研究区域 $\mathrm{NH}_{3}-\mathrm{N}$ 和 SRP 释放速率均大于零, 即表现为相应污染物自沉积物向上覆水体释放, 沉积物扮演着明显的污染源角色. 分析结果显示, 研究区域各采样点 $\mathrm{NH}_{3}-\mathrm{N}$ 释放速率在 $26.36 \sim 42.73 \mathrm{mg} /\left(\mathrm{m}^{2} \cdot \mathrm{d}\right)$ 之间, 平均 $\mathrm{NH}_{3}-\mathrm{N}$ 释放速率 为 $32.44 \mathrm{mg} /\left(\mathrm{m}^{2} \cdot \mathrm{d}\right)$, 空间分布差异较小 (空间变异系数为 $19.07 \%$ ). 其中靠近双桥河河口的 $\mathrm{CH} 2$ 采样点处 $\mathrm{NH}_{3}-\mathrm{N}$ 释放速率最高, $\mathrm{CH} 7$ 采样点处的 $\mathrm{NH}_{3}-\mathrm{N}$ 释放速率最低.

整个东巢湖近城市湖湾采样点释放速率在 $0.37 \sim 2.17 \mathrm{mg} /\left(\mathrm{m}^{2} \cdot \mathrm{d}\right)$ 之间, $\mathrm{SRP}$ 平均释放速率为 $1.25 \mathrm{mg} /$ $\left(\mathrm{m}^{2} \cdot \mathrm{d}\right.$ ). SRP 释放速率空间差异性明显 (变异系数为 $46.86 \%$ ). 其中 CH5 采样点处的 SRP 释放速率最高, 靠近河口的采样点 $\mathrm{CH} 1 、 \mathrm{CH} 2 、 \mathrm{CH} 4$ 处 SRP 释放速率较低, 其中 CH1 处的 SRP 释放速率最低.
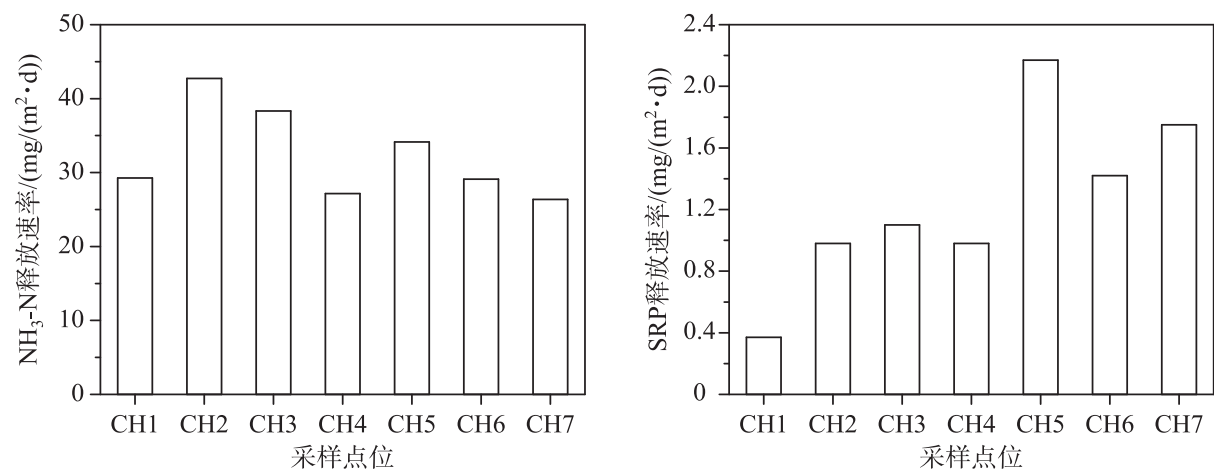

图 2 东巢湖近城市湖湾各采样点沉积物氨氮和磷酸盐释放速率

Fig.2 Release rate of $\mathrm{NH}_{3}-\mathrm{N}$ and SRP from different sediment cores in near city areas of east Lake Chaohu

\section{3 沉积物一水微界面溶解氧剖面分布特征}

在进行沉积物一水微界面 DO 剖面分析时, 对每个样品都做了 3 次平行测定. 在获得测量结果后, 将每 个样品的 3 组平行数据进行一元方差分析 $(t$ 检验, $\alpha=0.05)$, 结果显示每个采样点沉积物一水微界面 DO 平 行测定结果间均不存在显著差异 $(P>0.05)$, 所获得相应数据平行性较好. 因此, 以 3 组测量结果的平均值代 表每个点位沉积物一水微界面相应深度的 DO 浓度, 获得对应点位 DO 在沉积物一水微界面处的剖面分布特 征 (图 3). 结果显示, 对于所有点位样品, 沉积物一水微界面 DO 分布均呈现出界面水中浓度较高、在沉积 物一水微界面处迅速下降、并在沉积物中达到一定深度后消耗殆尽的特点. 即: 沉积物一水微界面 DO 浓度分 布均呈现出自界面水向沉积物方向, 随沉积物深度逐渐增加其 DO 浓度而不断降低的特征.

沉积物一水微界面 DO 分析结果表明, 各点位上覆水均处于好氧状态 ${ }^{[44]}$, 没有出现缺氧或者厌氧等 DO 不足或者缺失的情况. 这也就造成了 DO 在微表层沉积物中的普遍存在与渗透, 其 OPD 在 $3 \sim 10 \mathrm{~mm}$ 之间, 平均 $\mathrm{OPD}$ 为 $5.3 \mathrm{~mm}$. 具体到各点位而言, 其 $\mathrm{OPD}$ 差别较大 (图 4). 其中 CH6 处的 OPD 最大, 为 $10 \mathrm{~mm}, \mathrm{CH} 1$ 处的 OPD 最小, 为 $3 \mathrm{~mm}$, 其余点位的 OPD 差别不明显, 在 3.9 6 $\mathrm{mm}$ 之间.

在获得沉积物一水微界面 DO 分布的基础上, 进一步计算单位体积沉积物 DO 消耗速率, 结果如图 3 所 示. 所有采样点的 DO 大量消耗主要出现在 $0 \sim 2 \mathrm{~mm}$ 深度的沉积物有氧表层中, 且大部分采样点最大的 DO 


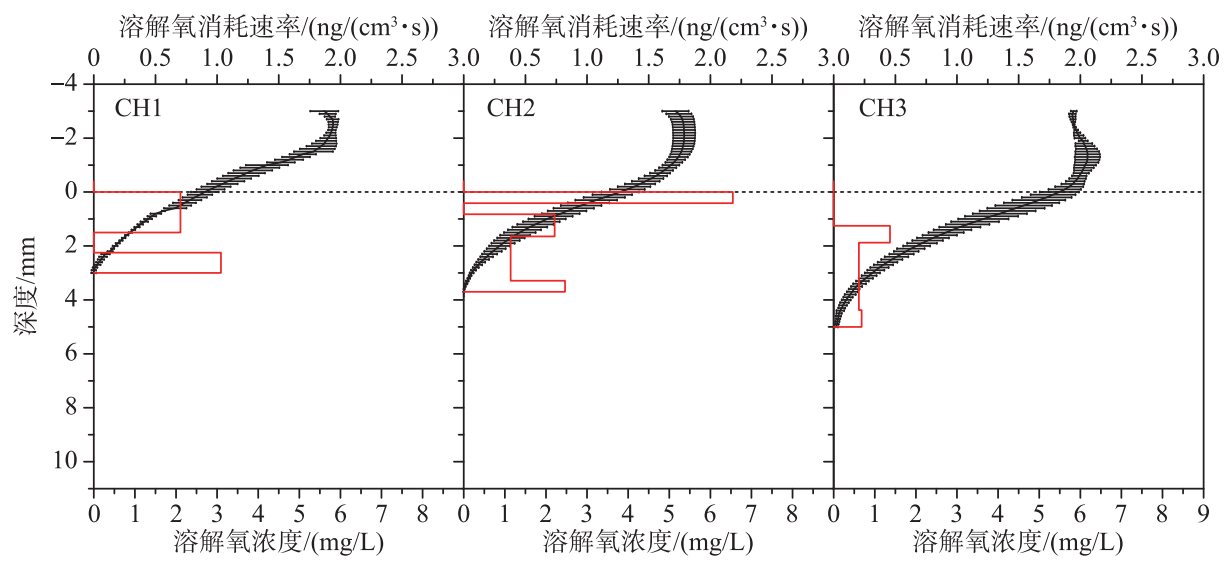

溶解氧消耗速率 $/\left(\mathrm{ng} /\left(\mathrm{cm}^{3} \cdot \mathrm{s}\right)\right) \quad$ 溶解氧消耗速率 $/\left(\mathrm{ng} /\left(\mathrm{cm}^{3} \cdot \mathrm{s}\right)\right) \quad$ 溶解氧消耗速率 $/\left(\mathrm{ng} /\left(\mathrm{cm}^{3} \cdot \mathrm{s}\right)\right)$

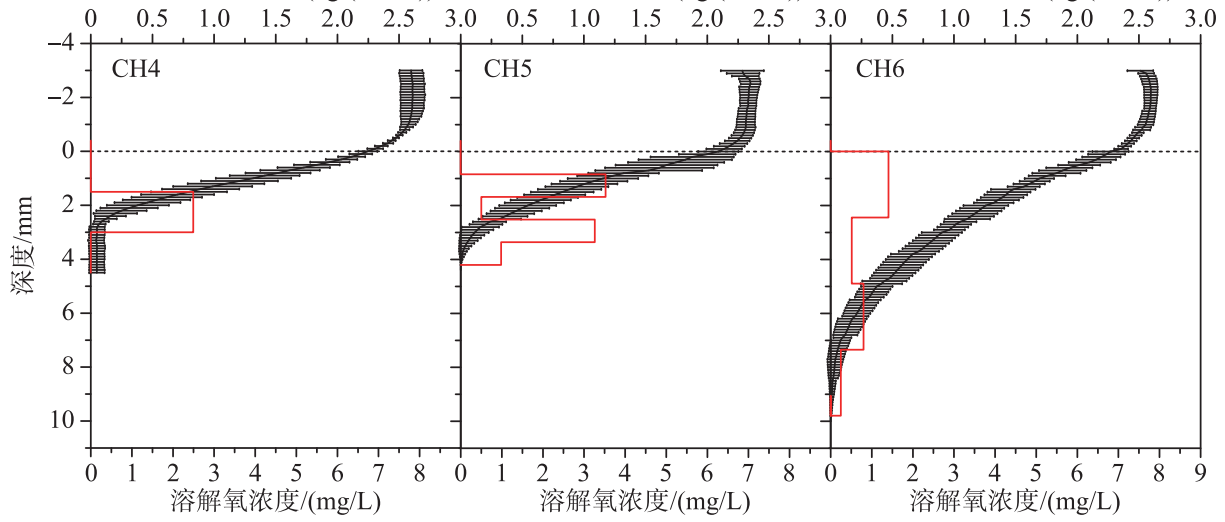

溶解氧消耗速率 $/\left(\mathrm{ng} /\left(\mathrm{cm}^{3} \cdot \mathrm{s}\right)\right)$

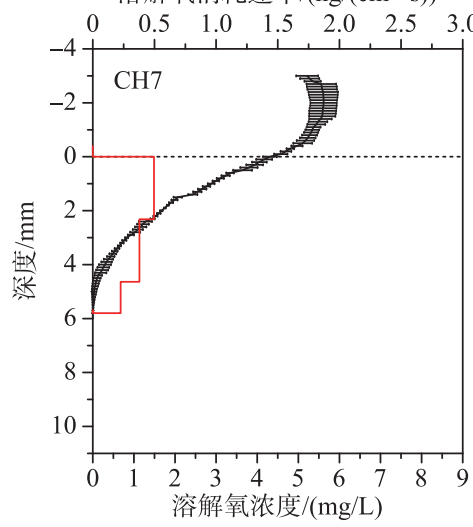

图 3 沉积物一水微界面溶解氧浓度及沉积物溶解氧消耗速率剖面分布特征 (黑线表示沉积物一水界面 溶解氧分布曲线, 红线表示单位体积沉积物溶解氧消耗速率, 纵坐标 0 处为沉积物一水界面 (SWI), 纵坐标为正表示 SWI 之下沉积物深度,纵坐标为负表示 SWI 之上界面水厚度)

Fig.3 Dissolved oxygen profiles and oxygen consumption rates in sediment-water micro-interfaces from different sampling sites ( The black line represents the dissolved oxygen distribution curve at the sediment-water interface (SWI). The red line represents the oxygen consumption rates. To the axis of ordinate, the ordinate 0 represents the position of the SWI, positive ordinates represent sediment depth below the SWI and negative ordinates represent the depth of the boundary layer water above the SWI) 
消耗速率均出现在这个范围之间, 7 个采样点的平均 DO 消耗速率为 $0.49 \mathrm{ng} /\left(\mathrm{cm}^{3} \cdot \mathrm{s}\right)$. 但具体而言, 各采样 点的平均 DO 消耗速率差别较大, 在 $0.19 \sim 0.82 \mathrm{ng} /\left(\mathrm{cm}^{3} \cdot \mathrm{s}\right)$ 之间. 其中 $\mathrm{CH} 1$ 点位的平均 DO 消耗速率较其他 采样点大, 为 $0.82 \mathrm{ng} /\left(\mathrm{cm}^{3} \cdot \mathrm{s}\right)$. 平均 DO 消耗速率最低的点位为 $\mathrm{CH} 3$, 其消耗速率为 $0.19 \mathrm{ng} /\left(\mathrm{cm}^{3} \cdot \mathrm{s}\right), \mathrm{CH} 6$ 点位的平均 DO 消耗速率较低, 为 $0.23 \mathrm{ng} /\left(\mathrm{cm}^{3} \cdot \mathrm{s}\right)$, 其他点位的平均 DO 消耗速率差别不大, 在 $0.38 \sim 0.69$ $\mathrm{ng} /\left(\mathrm{cm}^{3} \cdot \mathrm{s}\right)$ 之间.

\section{4 沉积物一水微界面溶解氧扩散通量}

沉积物一水微界面 DO 扩散通量是微表层沉积物氧化还原条件的重要表征, 其大小反映界面水中 DO 向 微表层沉积物的扩散输移能力, 同时受水体温度、界面水 DO 浓度、界面 DO 消耗速率及扩散边界层厚度等 多因素共同影响. 一般而言, 在 DO 比较充足的水体中, 沉积物一水微界面处 DO 消耗速率较高时, 受浓度梯 度影响其 DO 扩散通量也相对较高; 而在 DO 含量较低甚至缺失的水体中, 其沉积物一水微界面 DO 扩散通 量也相应较低甚至为零. 本研究获得的东巢湖近城市湖湾不同区域沉积物一水微界面 DO 扩散通量如图 4 所示. 整体而言, 研究区域各点位均表现出一定程度的沉积物一水微界面 DO 扩散能力, 扩散通量在 2.82 $6.38 \mathrm{mmol} /\left(\mathrm{m}^{2} \cdot \mathrm{d}\right)$ 之间, 平均扩散通量为 $4.56 \mathrm{mmol} /\left(\mathrm{m}^{2} \cdot \mathrm{d}\right)$. 其中, CH1 点位扩散通量最高, 达到 $6.38 \mathrm{mmol} /\left(\mathrm{m}^{2} \cdot \mathrm{d}\right)$; CH6 点位最低, 为 $2.82 \mathrm{mmol} /\left(\mathrm{m}^{2} \cdot \mathrm{d}\right)$. 值得注意的是, 各采样点 DO 扩散通量空间分布 差异明显, 空间变异系数为 $25.17 \%$. 其中靠近河口的采样点 CH1、CH2、CH4 的 DO 扩散通量相对较高, 分别 为 $6.38 、 4.80$ 和 $5.36 \mathrm{mmol} /\left(\mathrm{m}^{2} \cdot \mathrm{d}\right)$.

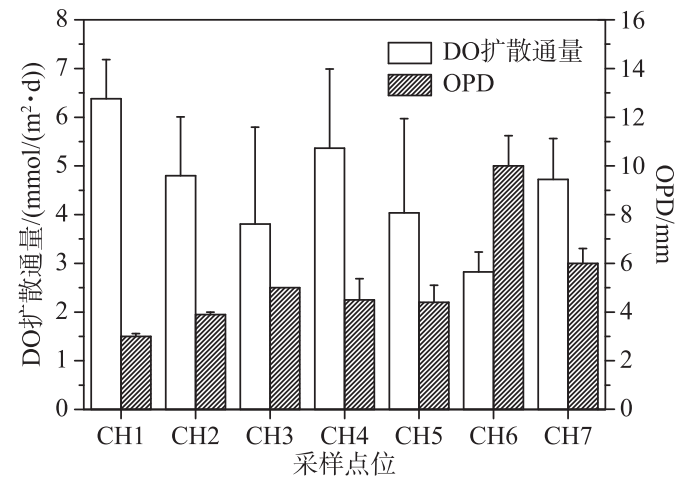

图 4 不同采样点位沉积物一水微界面溶解氧扩散通量及穿透深度 $(\mathrm{OPD})$

Fig.4 Dissolved oxygen diffusion fluxes and oxygen penetration depth (OPD) at sediment-water micro-interfaces of different sediments

\section{3 讨论}

\section{1 东巢湖近城市湖湾氮、磷释放对水体富营养化的影响}

湖泊沉积物是湖泊水环境污染物的主要蓄积及迁移转化场所, 当受污染底泥在氮、磷污染物蓄积到较 深程度之后, 会在水动力等物理扰动、水环境氧化还原状态变化、间隙水中污染物浓度上升等条件下,通过 底泥再悬浮、浓度梯度扩散、物理和生物扰动、赋存形态变化等过程向上覆水体释放,使原来已经汇集到沉 积物中的氮、磷污染物再次进人上覆水体, 实现底泥高浓度蓄积污染物对上覆水体的二次污染. 在这种情况 下,底泥完成了从污染物汇集场所到污染物释放源头的角色转变,成为水体中氮、磷污染物的“污染源”.

本研究结果显示, 东巢湖近城市湖湾沉积物 TN 和 TP 含量整体较高, 平均含量分别达到 3245.36 和 $535.29 \mathrm{mg} / \mathrm{kg}$, 参照美国环境保护署的有关评价标准, 已整体处于明显的污染状态. 巢湖是受人类活动影响 剧烈的大型富营养化浅水湖泊, 历史上长期受到农业面源、工业生产、城市点源等氮、磷排放的影响, 使得其 湖体及沉积物中氮、磷营养盐类物质含量普遍较高, 本研究获得的东巢湖近城市湖湾沉积物 TN、TP 含量较 高这一现象与已有研究结果类似 ${ }^{[45]}$. 从空间分布来看, 北部靠近巢湖市区河口附近的 CH1、CH3、CH4 等采 样点沉积物 TN 和 TP 含量相对较低, 底泥疏浚工程的实施可能是这些点位氮、磷含量较低的原因 ${ }^{[46]}$. 
沉积物内源氮、磷营养盐释放模拟表明, 本研究区域沉积物 $\mathrm{NH}_{3}-\mathrm{N}$ 和 SRP 释放速率均为正值,沉积物 具有明显的向上覆水体释放氮、磷污染物的潜力. 其中 $\mathrm{NH}_{3}-\mathrm{N}$ 平均释放速率为 $32.44 \mathrm{mg} /\left(\mathrm{m}^{2} \cdot \mathrm{d}\right)$, 这一释放 速率低于西巢湖 $\mathrm{NH}_{3}-\mathrm{N}$ 释放速率 ${ }^{[47]}$, 与滇池草海水域 $\mathrm{NH}_{3}-\mathrm{N}$ 释放速率相似 $\left(31.5 \mathrm{mg} /\left(\mathrm{m}^{2} \cdot \mathrm{d}\right)\right)^{[48]}$. 采样点 $\mathrm{CH} 2$ 处 $\mathrm{NH}_{3}-\mathrm{N}$ 释放速率最高, 这可能与该处 TN 含量较高且沉积物一水微界面处 DO 浓度较低 $(3.8 \mathrm{mg} / \mathrm{L})$ 有 关. 各点位处的 SRP 释放速率差别较大, 在 $0.37 \sim 2.17 \mathrm{mg} /\left(\mathrm{m}^{2} \cdot \mathrm{d}\right)$ 之间, 普遍低于西巢湖 SRP 释放速率 ${ }^{[47]}$, 与滇池福保湾底泥内源 SRP 释放速率 $\left(0.90 \sim 2.06 \mathrm{mg} /\left(\mathrm{m}^{2} \cdot \mathrm{d}\right)\right)$ 相似 ${ }^{[36]}$. 其中, 靠近北岸一侧的采样点的 SRP 释放速率明显小于其他点位, 沉积物整体 TP 含量较低可能是这一现象发生的主要原因.

东巢湖水体已经处于中度富营养化状态 ${ }^{[49]}$, 水体氮、磷营养盐浓度长期较高是造成这一现象的直接原 因. 本研究结果表明, 东巢湖近城市湖湾沉积物内源氮、磷营养盐依旧扮演水体相应污染物来源的角色, 来 自沉积物的 $\mathrm{NH}_{3}-\mathrm{N}$ 和 SRP 的释放将毫无疑问进一步加剧研究区域水体富营养化状态. 进一步通过面积 (泰 森多边形法划分) 权加法计算, 结果表明本研究东巢湖近城市湖湾沉积物单位面积年释 $\mathrm{NH}_{3}-\mathrm{N}$ 和 SRP 分别 达到 11.53 和 $0.51 \mathrm{t} /\left(\mathrm{km}^{2} \cdot \mathrm{a}\right)$. 与我国几个富营养化湖泊沉积物中的相比 (表 2$)$, 东巢湖近城市湖湾的沉积 物氮、磷年释放量较大, 该区域沉积物氮、磷的释放将进一步加剧或维持水体富营养化状态, 对东巢湖水环 境质量具有深刻的影响.

表 2 不同湖泊沉积物内源氨氮和磷酸盐释放量

Tab. $2 \mathrm{NH}_{3}-\mathrm{N}$ and SRP release of sediments from different lakes

\begin{tabular}{|c|c|c|c|c|c|c|}
\hline 湖泊 & $\begin{array}{c}\text { 全年氮释量/ } \\
(\mathrm{t} / \mathrm{a})\end{array}$ & $\begin{array}{c}\text { 单位面积氮释量/ } \\
\left(\mathrm{t} /\left(\mathrm{km}^{2} \cdot \mathrm{a}\right)\right)\end{array}$ & $\begin{array}{c}\text { 全年磷释量/ } \\
(\mathrm{t} / \mathrm{a})\end{array}$ & $\begin{array}{c}\text { 单位面积磷释量/ } \\
\left(\mathrm{t} /\left(\mathrm{km}^{2} \cdot \mathrm{a}\right)\right)\end{array}$ & $\begin{array}{l}\text { 面积/ } \\
\mathrm{km}^{2}\end{array}$ & 参考文献 \\
\hline 东巢湖 & 311.31 & 11.53 & 13.78 & 0.51 & 27 & 本研究 \\
\hline 太湖 & 1756 & 0.75 & 64.60 & 0.028 & 2338 & {$[50]$} \\
\hline 滇池福保湾 & $49.9 \pm 8.8$ & $49.9 \pm 8.8$ & $0.79 \pm 0.53$ & $0.79 \pm 0.53$ & 1 & {$[36]$} \\
\hline 骆马湖 & $1113.2 \pm 71.3$ & $4.4 \pm 0.3$ & $12.50 \pm 0.95$ & $0.05 \pm 0.01$ & 253 & {$[51]$} \\
\hline 北里湖 & 0.0037 & 0.0106 & 0.0057 & 0.0163 & 0.35 & [52] \\
\hline
\end{tabular}

\section{2 沉积物一水微界面溶解氧分布对内源氮、磷释放的影响}

沉积物一水微界面的 DO 分布影响着湖泊中氮、磷的生物地球化学循环, 从而影响到沉积物一水界面的 氮、磷交换. 上覆水体 DO 浓度、表层沉积物有机质分解矿化、表层沉积物微生物及底栖动物或微藻生命活 动、沉积物孔隙度及其他相应物理性质等均能影响沉积物一水微界面 DO 溶存与分布特征. 在海洋沉积物 中, DO 穿透深度较深, 可高达近 $10 \mathrm{~cm}^{[53]}$. 在湖泊沉积物中, 尤其是富营养化湖泊中, DO 穿透深度相对较 浅, 其穿透深度一般在 $2.5 \mathrm{~mm}^{[33]}$, 有时甚至仅为 $50 \mu \mathrm{m}^{[31]}$. 本研究中, 各点位 DO 穿透深度为 $3 \sim 10 \mathrm{~mm}$, 平 均为 $5.3 \mathrm{~mm}$, 空间差异较大. 其中 CH1 点位 OPD 最小, 只有 $3 \mathrm{~mm}$, 该点位沉积物一水微界面处 DO 含量较低 $(2.7 \mathrm{mg} / \mathrm{L})$ 是造成其 OPD 较小的直接原因. 本研究区域沉积物一水微界面 DO 扩散通量普遍较高, 这使得 微表层沉积物可以得到较好的 DO 补充, 从而维持良好的氧化环境. 相比较而言, 靠近河口的 CH1、CH2、 CH4 等采样点沉积物一水微界面 DO 扩散通量相对较高, 界面水与微界面间 DO 浓度梯度较大 (CH1) 以及河 口水流影响造成水体扰动 $\left(\mathrm{CH}_{2}\right.$ 和 $\left.\mathrm{CH}_{4}\right)$ 可能是这一现象发生的主要原因 ${ }^{[54]}$.

在底层水体或沉积物一水微界面 DO 充足的情况下, 相应环境往往处于良好的氧化状态, 沉积物氮、磷 释放速率一般较低; 反之, 在 DO 缺失或不足的情况下, 相应环境处于弱还原或还原性状态, 其氮、磷营养盐 释放则相应增强 ${ }^{[55]}$. 本次研究中并没有控制上覆水中的 DO 作为变量, 各点位上覆水均处于好氧状态, 因此 并没在 DO 与氮、磷的释放速率间发现显著相关关系 $(P>0.05)$, 这与已有研究结果类 ${ }^{\text {似 }}{ }^{[56]}$. 然而, 这并不说 明 DO 对沉积物氮、磷营养盐释放的影响可以被忽略不计, 沉积物中 DO 分布状态与其氮、磷负荷的叠加可 能对沉积物氮、磷释放造成复合影响. 本研究分析显示 (图 5, 图 6), 当 TN 含量较高且 OPD 较小时, 沉积物 $\mathrm{NH}_{3}-\mathrm{N}$ 释放速率最大; 同样地, 在 TP 含量较高且 OPD 较小时, 相应沉积物 SRP 释放速率最大. 因此可以认 为, 沉积物一水微界面 DO 浓度的高低及穿透深度的大小, 能与沉积物中氮、磷营养盐含量一起影响沉积物 氮、磷释放, 当沉积物氮、磷污染较重时, 低 DO 穿透深度更有利于氮、磷污染物从沉积物向上覆水体释放. 


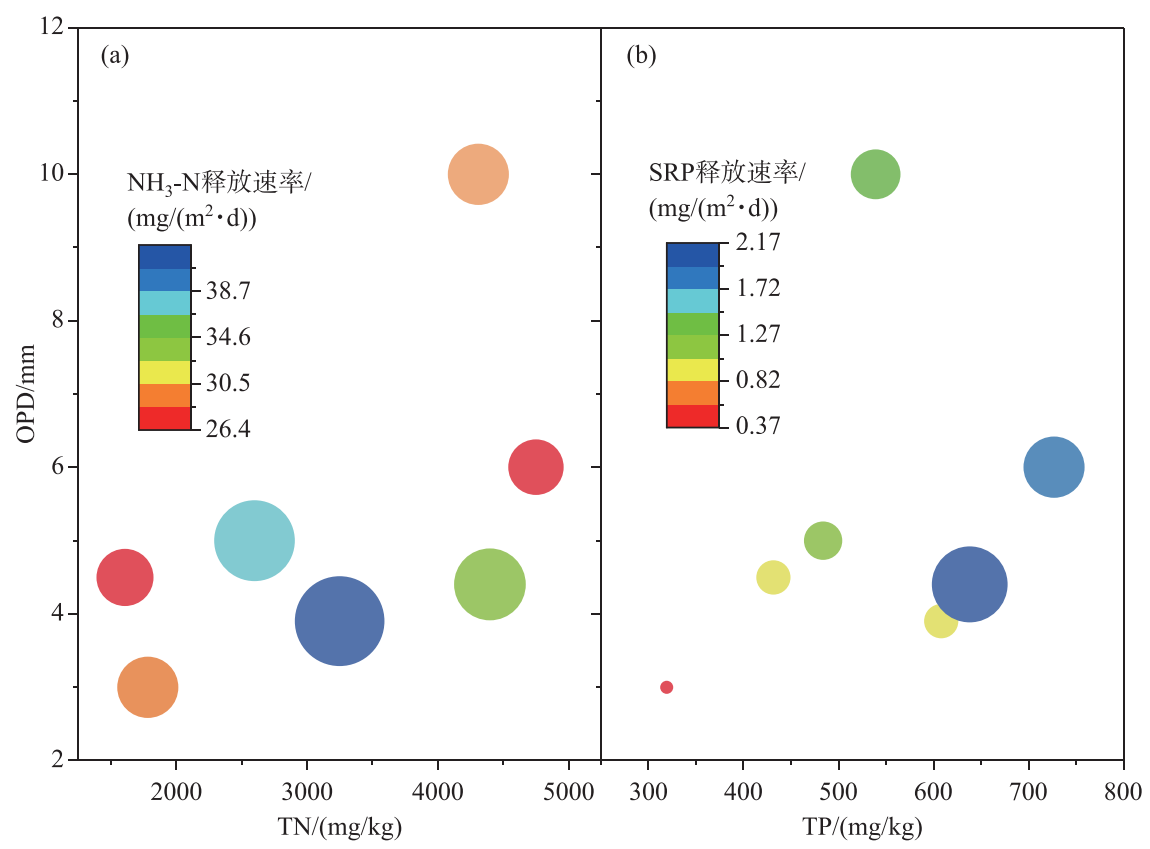

图 5 东巢湖近城市湖湾沉积物氨氮/磷酸盐释放速率气泡图

Fig.5 Bubble diagram of release rates for $\mathrm{NH}_{3}-\mathrm{N}$ and SRP in sediments of near city areas of east Lake Chaohu
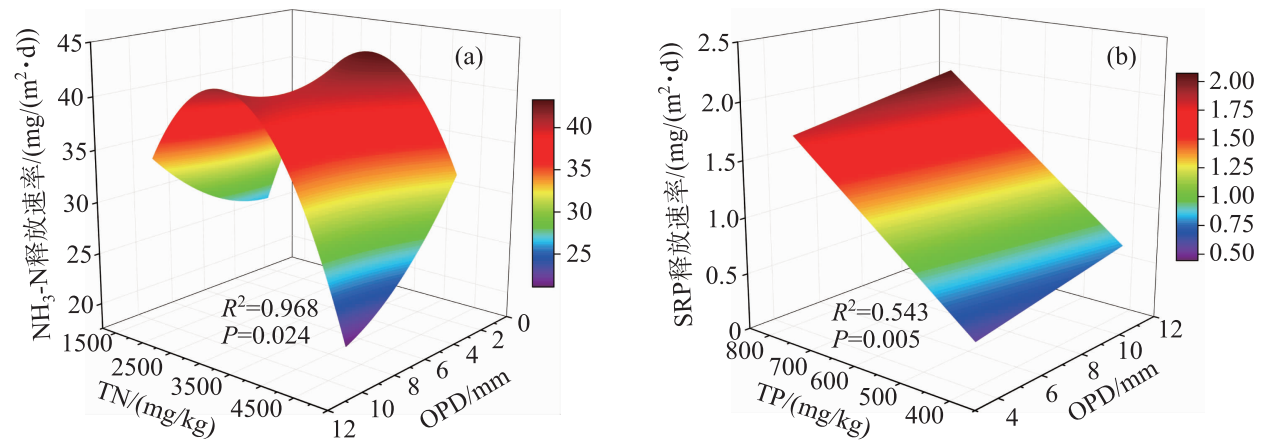

图 6 东巢湖近城市湖湾沉积物氨氮/磷酸盐释放速率与 TN/TP 和 OPD 的关系模拟

Fig.6 Relationships of sediment release rates of $\mathrm{NH}_{3}-\mathrm{N} / \mathrm{SRP}$, TN/TP, and OPD in sediments of near city areas of east Lake Chaohu

\section{4 结论}

东巢湖近城市湖湾表层沉积物氮、磷营养盐蓄积较高, 其 TN 和 TP 平均含量分别达到 3245.36 和 535.29 $\mathrm{mg} / \mathrm{kg}$, 沉积物总体处于 TN 重度污染和 TP 中度污染状态. 沉积物内源氮、磷释放模拟研究表明: 研究区域 沉积物 $\mathrm{NH}_{3}-\mathrm{N}$ 和 $\mathrm{SRP}$ 释放能力较强, 其中 $\mathrm{NH}_{3}-\mathrm{N}$ 释放速率在 $26.36 \sim 42.73 \mathrm{mg} /\left(\mathrm{m}^{2} \cdot \mathrm{d}\right)$ 之间, SRP 释放速率 在 $0.37 \sim 2.17 \mathrm{mg} /\left(\mathrm{m}^{2} \cdot \mathrm{d}\right)$ 之间, 两者在各点位均表现为自沉积物向上覆水体的正释放, 东巢湖近城市湖湾沉 积物明显已成为其水体 $\mathrm{NH}_{3}-\mathrm{N}$ 和 $\mathrm{SRP}$ 的污染来源, 对该湖区水体富营养化具有重要贡献. 研究区域上覆水 体处于好氧状态, 沉积物一水微界面 DO 穿透深度 (OPD) 分布在 3 10 mm 之间, 平均 DO 扩散通量为 4.56 $\mathrm{mmol} /\left(\mathrm{m}^{2} \cdot \mathrm{d}\right)$, 单位体积沉积物平均 DO 消耗速率为 $0.49 \mathrm{ng} /\left(\mathrm{cm}^{3} \cdot \mathrm{s}\right)$, 沉积物一水微界面 DO 穿透深度和扩 
散能力均较好. 综合分析显示: 沉积物一水界面 $\mathrm{NH}_{3}-\mathrm{N}$ 和 SRP 释放能力与表层沉积物 TN/TP 物质含量及沉 积物一水微界面 DO 穿透深度有关, 在沉积物氮、磷污染较重的情况下, DO 穿透深度越低则氮、磷污染物越 趋于从沉积物向上覆水体释放, 进而有利于水体中相应污染物的积累并贡献于富营养化状态的维持. 然而, 沉积物一水界面 DO 扩散模式与边界层内氮、磷营养盐迁移转化的关系非常复杂, 有关关键过程依旧缺乏直 接的实证,相关影响机制还需进一步研究.

\section{5 参考文献}

[ 1 ] Yang GS, Ma RH, Zhang L et al. Lake status, major problems and protection strategy in China. J Lake Sci, 2010,22 (6) : 799-810. DOI: 10.18307/2010.0601. [杨桂山, 马荣华, 张路等. 中国湖泊现状及面临的重大问题与保护策 略. 湖泊科学, 2010, 22(6): 799-810.]

[ 2 ] Hellsten SK, Virtanen MO, Nenonen OS et al. Relative importance of internal sources of phosphorus and organic matter in northern finnish reservoirs. Waterence \& Technology, 1993, 28(6) : 85-94. DOI: 10.2166/wst.1993.0132.

[ 3 ] Søndergaard M, Jensen JP, Jeppesen E. Role of sediment and internal loading of phosphorus in shallow lakes. Hydrobiologia , 2003, 506/507/508/509(1/2/3) : 135-145. DOI: 10.1023/b:hydr.0000008611.12704.dd.

[ 4 ] Phillips IR, Burton ED, Hawker DW. Effect of diffusion and resuspension on nutrient release from submerged sediments. Toxicological \& Environmental Chemistry, 2005, 87(3) : 373-388. DOI: 10.1080/02772240500132216.

[ 5 ] Jeppesen E, Meerhoff M, Jacobsen BA et al. Restoration of shallow lakes by nutrient control and biomanipulation-the successful strategy varies with lake size and climate. Hydrobiologia, 2007, 581(1) : 269-285. DOI: 10.1007/s10750-0060507-3.

[ 6 ] Li HY, Liu L, Li MY et al. Effects of $\mathrm{pH}$, temperature, dissolved oxygen, and flow rate on phosphorus release processes at the sediment and water interface in storm sewer. Journal of Analytical Methods in Chemistry, 2013: 1-7. DOI: 10.1155/ 2013/104316.

[ 7 ] Wu FC, Wan GJ, Huang RG. Biogeochemical processes of nutrition elements at the sediment-water interface of lakes I . Nitrogen cycling and its environmental impacts. Acta Mineralogica Sinica , 1996, 16(4) : 403-409. [吴丰昌, 万国江, 黄 荣贵. 湖泊沉积物-水界面营养元素的生物地球化学作用和环境效应 I. 界面氮循环及其环境效应. 矿物学报, 1996, 16(4) : 403-409.]

[ 8 ] Gao L, Zhou JM. Phosphorus cycle between sediments and water in eutrophic lakes. Chinese Journal of Soil Science, 2004, 35(4) : 512-515. [高丽，周健民. 磷在富营养化湖泊沉积物-水界面的循环. 土壤通报, 2004, 35(4) : 512-515.]

[ 9 ] Fan CX. Advances and prospect in sediment-water interface of lakes: A review. J Lake Sci, 2019, 31(5): 1191-1218. DOI: 10.18307/2019.0514. [范成新. 湖泊沉积物一水界面研究进展与展望. 湖泊科学, 2019, 31(5) : 1191-1218.]

[10] Li B, Wang ZQ. Estimation of nitrogen and phosphorus release rates at sediment-water interface of Nansi Lake, China. Advanced Materials Research, 2012, 573/574: 573-577. DOI: 10.4028/www.scientific.net/amr.573-574.573.

[11] Cheng XJ, Guo ZR, Liu G et al. Study on flux of nitrogen and phosphorus across the interface of sediment-water and their diffusion areas in seawater at the aquaculture region of Daya Bay. Journal of Tropical Oceanography, 2014, 33(4) : 77-84. [程香菊, 郭振仁, 刘国等. 大亚湾养殖区沉积物-水界面氮磷的释放通量及其在水体中的扩散迁移. 热带海洋学 报, 2014, 33(4): 77-84.]

[12] Cheng XJ, Zeng YX, Guo ZR et al. Diffusion of nitrogen and phosphorus across the sediment-water interface and in seawater at aquaculture areas of Daya Bay, China. International Journal of Environmental Research and Public Health, 2014,11 (2) : 1557-1572. DOI: 10.3390/ijerph110201557.

[13] Liu HY, Li H, Deng S et al. Environmental release of phosphorus and nitrogen in the surface sediments of Dianchi Lake, China. Advanced Materials Research, 2013, 726/727/728/729/730/731 : 1479-1483. DOI: 10.4028/www.scientific.net/ amr.726-731.1479.

[14] Xu CR. Research on nitrogen and phosphorus release from sediments in small inland freshwater lakes. Advanced Materials Research, 2013, 864/865/866/867: 248-255. DOI: 10.4028/www.scientific.net/amr.864-867.248.

[15] Hou DK, He J, Lv CW et al. Effects of environmental factors on nutrients release at sediment-water interface and assessment of trophic status for a typical shallow lake, northwest China. The Scientific World Journal, 2013: 1-16. DOI: 10. $1155 / 2013 / 716342$. 
[16] Zhang L, Wang SR, Wu ZH. Coupling effect of $\mathrm{pH}$ and dissolved oxygen in water column on nitrogen release at water-sediment interface of Erhai Lake, China. Estuarine, Coastal and Shelf Science, 2014, 149: 178-186. DOI: 10.1016/j. ecss. 2014.08.009.

[17] Wang SR, Jin XC, Bu QY et al. Effects of dissolved oxygen supply level on phosphorus release from lake sediments. Colloids and Surfaces A: Physicochemical and Engineering Aspects, 2008, 316(1/2/3) : 245-252. DOI: 10.1016/j.colsurfa.2007.09.007.

[18] Hu QH, Zhu YM, Song J et al. Effects of $\mathrm{pH}$ and Eh on release of nitrogen and phosphorus from sediments of West Lake. Journal of Zhejiang University-Science A, 2003, 4(3) : 358-362. DOI: 10.1631/jzus.2003.0358.

[19] Jiang YS, Li XC, Xing YH et al. Impacts of disturbance on release of total nitrogen and total phosphorus from surficial sediments of Dongping Lake. Environmental Science \& Technology, 2010, 33(8): 41-44. [姜永生, 李晓晨, 邢友华等. 扰 动对东平湖表层沉积物中氮磷释放的影响. 环境科学与技术, 2010, 33(8): 41-44.]

[20] Sun XJ, Qin BQ, Zhu GW et al. Release of colloidal N and P from sediment of lake caused by continuing hydrodynamic disturbance. Huanjing Kexue/Environmental Science, 2007, 28(6) : 1223-1229.

[21] Su YP, Zheng DX, Lin WZ et al. Phosphorus forms in sediment and the release potential of phosphorus to water in eutrophic Shanzi reservoir, Fujian Province. J Lake Sci, 2005, 17(4) : 311-316. DOI: 10.18307/2005.0405. [苏玉萍, 郑 达贤，林婉珍等. 福建省富营养化水库沉积物磷形态及对水体的贡献. 湖泊科学, 2005, 17(4) : 311-316.]

[22] Wang SR, Jin XC, Jiao LX et al. Nitrogen fractions and release in the sediments from the shallow lakes in the middle and lower reaches of the Yangtze River area, China. Water, Air, and Soil Pollution, 2007, 187(1/2/3/4) : 5-14. DOI: 10. 1007/s11270-007-9453-6.

[23] Zhang L, Fan CX, Wang JJ et al. Nitrogen and phosphorus forms and release risks of lake sediments from the middle and lower reaches of the Yangtze River. J Lake Sci, 2008, 20(3) : 263-270. DOI: 10.18307/2008.0301. [张路, 范成新, 王 建军等. 长江中下游湖泊沉积物氮磷形态与释放风险关系. 湖泊科学, 2008, 20(3): 263-270.]

[24] Wang H, Holden J, Spera K et al. Phosphorus fluxes at the sediment-water interface in subtropical wetlands subjected to experimental warming: A microcosm study. Chemosphere, 2013, 90(6) : 1794-1804. DOI: 10.1016/j.chemosphere.2012. 08.044 .

[25] Middelburg JJ, Levin LA. Coastal hypoxia and sediment biogeochemistry. Biogeosciences, 2009, 6(7) : 1273-1293. DOI: 10.5194/bg-6-1273-2009.

[26] Hamilton-Taylor J, Davison W eds. Redox-driven cycling of trace elements in lakes. Physics and chemistry of lakes. Berlin, Heidelberg: Springer Berlin Heidelberg, 1995: 217-263. DOI: 10.1007/978-3-642-85132-2_8

[27] Su XX, He Q, Mao YF et al. Dissolved oxygen stratification changes nitrogen speciation and transformation in a stratified lake. Environmental Science and Pollution Research, 2019, 26(3) : 2898-2907. DOI: 10.1007/s11356-018-3716-1.

[28] Ruttenberg KC. The global phosphorus cycle. Treatise on geochemistry. Elsevier, 2003: 585-643. DOI: 10.1016/b0-08043751-6/08153-6.

[29] Xu SB, Gu XH, Cai CF, et al. Effect on the release of nitrogen and phosphorus from sediment of the east Taihu by dissolved oxygen, water temperature and currents. Journal of Anhui Agricultural Sciences, 2011, 39(9) : 5175-5177, 5366. [徐升宝, 谷孝鸿, 蔡春芳等. 溶氧·水温和水流对东太湖沉积物中氮・磷释放的影响. 安徽农业科学, 2011, 39 (9) : 5175-5177, 5366.]

[30] Tang A, Wan J, Wang R et al. Importance of $\mathrm{pH}$, dissolved oxygen and light to phosphorus release from ditch sediments. Nature Environment \& Pollution Technology, 2015, 14(3) : 475-484.

[31] Shen QS, Liu C, Zhou QL et al. Effects of physical and chemical characteristics of surface sediments in the formation of shallow lake algae-induced black bloom. Journal of Environmental Sciences, 2013, 25(12) : 2353-2360. DOI: 10.1016/ s1001-0742 (12) 60325-8.

[32] Wang C, Shan BQ, Zhang H et al. Analyzing sediment dissolved oxygen based on microprofile modeling. Environmental Science and Pollution Research, 2014, 21 (17) : 10320-10328. DOI: 10.1007/s11356-014-2875-y.

[33] Zhang L, Gu XZ, Fan CX et al. Impact of different benthic animals on phosphorus dynamics across the sediment-water interface. Journal of Environmental Sciences, 2010, 22(11) : 1674-1682. DOI: 10.1016/s1001-0742(09)60305-3.

[34] Yu HB, Xi BD, Jiang JY et al. Environmental heterogeneity analysis, assessment of trophic state and source identification in Chaohu Lake, China. Environmental Science and Pollution Research, 2011, 18 ( 8 ) : 1333-1342. DOI: 10.1007/ 
s11356-011-0490-8

[35] Le C, Zha Y, Li Y et al. Eutrophication of lake waters in China: Cost, causes, and control. Environmental Management, 2010, 45(4) : 662-668. DOI: 10.1007/s00267-010-9440-3.

[36] Li B, Ding SM, Fan CX et al. Estimation of releasing fluxes of sediment nitrogen and phosphorus in Fubao Bay in Dianchi Lake. Environmental Science, 2008, 29(1) : 114-120. DOI: 10.13227/j.hjkx.2008.01.031. [李宝, 丁土明, 范成新等. 滇池福保湾底泥内源氮磷营养盐释放通量估算. 环境科学, 2008, 29(1) : 114-120.]

[37] Berg P, Risgaard-Petersen N, Rysgaard S. Interpretation of measured concentration profiles in sediment pore water. Limnology and Oceanography, 1998, 43(7) : 1500-1510. DOI: 10.4319/lo.1998.43.7.1500.

[38] Wang J, Zhao L, Wei H. Variable diffusion boundary layer and diffusion flux at sediment water interface in response to dynamic forcing over an intertidal mudflat. Chinese Science Bulletin, 2012, 57(8):656-665. [汪嘉宁, 赵亮, 魏皓. 潮滩 动力过程影响下扩散边界层和沉积物-水界面扩散通量的变化. 科学通报, 2012, 57 (8):656-665.]

[39] Ramsing N, Gundersen J. Seawater and gases - Tabulated physical parameters of interest to people working with microsensors in marine systems. Version 2.0. Unisense Internal Report, 1994.

[40] Shen QS, Shao SG, Wang ZD et al. Simulation of black bloom in Moon Bay of Lake Taihu and physical and chemical responses of water and sediment. Advances in Water Science, 2011, 22(5): 710-719. [ 申秋实, 邵世光, 王兆德等. 太湖 月亮湾湖泛发生过程模拟及水土物化性质的响应. 水科学进展, 2011, 22(5): 710-719.]

[41] Wang SR ed. Sediment-water interface process of lakes. Beijing: Science Press, 2013. [王圣瑞. 湖泊沉积物-水界面过 程. 北京: 科学出版社, 2013.]

[42] Jing XC, Tu QY ed. Lake eutrophication survey specification: version 2.0. Beijing: China Environmental Science Press, 1990：164-188. [ 金相灿, 屠清瑛. 湖泊富营养化调查规范: 第 2 版. 北京: 中国环境科学出版社, 1990: 164-188.]

[43] Cieniawski S, Macdonald DD, Ingersoll CG eds. EPA-905-B02-001-A, A guidance manual to support the assessment of contaminated sediments in freshwater ecosystems. Chicago, Illinois, United States: Great Lakes National Program Office, 2002.

[44] Xiang SL, Tao SP, Wu DS. Exchange fluxes of phosphorus at the sediment-water interface in Lake Poyang. J Lake Sci, 2017, 29(2) : 326-333. DOI: 10.18307/2017.0208. [向速林, 陶术平, 吴代赦. 鄱阳湖沉积物和水界面磷的交换通 量. 湖泊科学, $2017,29(2): 326-333$.

[45] Wang YH, Qian SM, Xu NN et al. Characteristics of distribution of pollutants and evaluation in sediment in the east area of Chaohu Lake. Research of Environmental Sciences, 2004, 17 (6) : 22-26. DOI: 10.13198/j. res. 2004.06.24. wangyh. 006. [王永华, 钱少猛, 徐南妮等. 巢湖东区底泥污染物分布特征及评价. 环境科学研究, 2004, 17(6): 22-26.]

[46] Fan CX, Wang JQ, Yang XD eds. Background phosphorus in Lake Chaohu: The environmental effect and its control. Beijing: China Environment Science Press, 2012: 109-110. [范成新, 汪家权, 羊向东. 巢湖磷本底影响及其控制. 北 京: 中国环境科学出版社, 2012: 109-110.]

[47] Liu C, Shao SG, Shen QS et al. Use of multi-objective dredging for remediation of contaminated sediments: A case study of a typical heavily polluted confluence area in China. Environmental Science and Pollution Research, 2015, 22(22) : 1783917849. DOI: 10.1007/s11356-015-4978-5.

[48] Wang JJ, Shen J, Zhang L et al. Sediment-water nutrient fluxes and the effects of oxygen in Lake Dianchi and Lake Fuxian, Yunnan Province. J Lake Sci, 2010, 22(5) : 640-648. DOI: 10.18307/2010.0503. [王建军, 沈吉, 张路等. 云南 滇池和抚仙湖沉积物-水界面营养盐通量及氧气对其的影响. 湖泊科学, 2010, 22(5):640-648.]

[49] Zhu QC. Cause analysis and governance measures of eutrophication in Chaohu Lake. Anhui Agricultural Science Bulletin, 2017, 23(9) : 97-98. [ 朱庆春. 巢湖水体富营养化成因分析及治理对策. 安徽农学通报, 2017, 23(9) : 97-98. ]

[50] Di ZZ, Zhang H, Shan BQ. Status of internal nutrient loads and their effects on overlying water quality in Taihu Lake. Acta Scientiae Circumstantiae, 2015, 35(12) : 3872-3882. DOI: 10.13671/j.hjkxxb.2015.0087. [狄贞珍, 张洪, 单保庆. 太 湖内源营养盐负荷状况及其对上覆水水质的影响. 环境科学学报, 2015, 35(12) : 3872-3882.]

[51] Fan CX, Zhang L, Yang LY et al. Simulation of internal loadings of nitrogen and phosphorus in a lake. Oceanologia et Limnologia Sinica, 2002, 33(4) : 370-378. [范成新, 张路, 杨龙元等. 湖泊沉积物氮磷内源负荷模拟. 海洋与湖 沼, 2002, 33(4) : 370-378. ]

[52] Liu JJ, Dong CY, Song YQ et al. The seasonal variations of nitrogen and phosphorus release and its fluxes from the sediments of the Beili Lake in the Hangzhou West Lake. Acta Ecologica Sinica, 2012, 32(24) : 7932-7939. DOI: 10.5846/ 
stxb201204180556. [刘静静, 董春颖, 宋英琦等. 杭州西湖北里湖沉积物氮磷内源静态释放的季节变化及通量估 算. 生态学报, 2012, 32(24) : 7932-7939.]

[53] Cai WJ, Sayles FL. Oxygen penetration depths and fluxes in marine sediments. Marine Chemistry, 1996, 52(2) : 123-131. DOI: 10.1016/0304-4203(95)00081-x.

[54] Zheng YH, Zou HD, He Q et al. Influence of hydrodynamic conditions on the oxygen flux of sediment-water interface. $J$ Lake Sci, 2018, 30(6): 1552-1559. DOI: 10.18307/2018.0607. [郑阳华, 邹浩东, 何强等. 水动力条件对沉积物水界面氧通量的影响. 湖泊科学, 2018, 30(6): 1552-1559.]

[55] Fan CX, Morihiro A. Effects of aerobic and anaerobic conditions on exchange of nitrogen and phosphorus across sedimentwater interface in Lake Kasumigaura. J Lake Sci, 1997, 9(4) : 337-342. DOI : 10.18307/1997.0408. [范成新, 相崎守 弘. 好氧和厌氧条件对霞浦湖沉积物一水界面氮磷交换的影响. 湖泊科学, 1997, 9(4) : 337-342.]

[56] Zhang L, Fan CX, Wang JJ et al. Space-time dependent variances of ammonia and phosphorus flux on sediment-water interface in Lake Taihu. Environmental Science, 2006, 27(8): 1537-1543. DOI: 10.13227/j.hjkx.2006.08.011. [张路, 范成新, 王建军等. 太湖水土界面氮磷交换通量的时空差异. 环境科学, 2006, 27 (8) : 1537-1543.] 